Revista Iberoamericana. Vol. LXII, Núm. 175, Abril-Junio 1996; 485-494

\title{
EL GOCE DEL VERBO: LA NARRATIVA DE ARMANDO ROMERO'
}

\author{
POR \\ Augusto Escobar Mesa \\ Universidad de Antioquia
}

De José Asunción Silva a Octavio Paz, de Borges a Lezama Lima, de Guimarães Rosa a García Márquez se observa un diálogo que, según Romero, es una "ventana abierta por donde accedemos a esa fiesta de hallazgos, choques y reconocimientos, oposiciones que integran el caldo de cultivo latinoamericano" (Romero, Gente de pluma 12). Pero estas figuras cimeras y unas cuantas más, copan el espectro de los lectores, traductores y críticos de la literatura latinoamericana, porque la mayoría de las obras de los jóvenes escritores y paradójicamente en la era de las telecomunicaciones- permanece en un cierto limbo para los lectores y hasta para los mismos críticos por falta de circulación y divulgación, por los bajos tirajes de las ediciones, las difíciles condiciones económicas de los países latinoamericanos, el aislamiento y retraso cultural y por las restringidas políticas editoriales, confirmando aquello que hace tres décadas Ángel Rama llamara "la balcanización cultural" de América Latina (Rama 292). La obra literaria de Romero es una de las que, a pesar de su importancia en su novedad formal y acercamiento crítico de la realidad colombiana, sigue sin la divulgación y el reconocimiento que merece.

Su narrativa pone de presente no sólo la situación conflictiva del hombre colombiano de las últimas cuatro décadas y del hombre del presente de cualquier parte, sino también el goce con el lenguaje en tanto que límite y acicate de la creación. Su afán de experimentación con la palabra no es producto - por su exigencia de lectura- de una pose o artificio alguno

\footnotetext{
${ }^{1}$ Armando Romero (Cali, Colombia, 1944), licenciado en español y literatura de la Universidad del Valle (Colombia), máster y doctor en literatura latinoamericana de la Universidad de Pittsburgh (EE.UU.); poeta, cuentista, novelista, ensayista, editor, traductor. Viajero y residente en muchos países de América Latina y Europa. En Venezuela, país donde vivió varios años, fue promotor cultural, fundador de revistas literarias, editor de libros, traductor e investigador, guionista y director de cine. Es profesor de literatura latinoamericana de la Universidad de Cincinnati desde 1985. Ha publicado los siguientes libros: El demonio y su mano (cuentos, 1975), Los móviles del sueño (poemas, 1976), El poeta de vidrio (poemas, 1976), La casa de los vespertilios (cuentos, 1982), Del aire a la mano (poemas, 1983), Las palabras están en situación (ensayo, 1985), El nadaísmo o la búsqueda de una vanguardia (ensayo, 1988), Gente de pluma (ensayos, 1989), Las combinaciones debidas (poemas, 1989), La esquina del movimiento (cuentos, 1992), Un día entre las cruces (novela, 1993), Una mariposa en la escalera (selección de cuentos publicados, 1993). Numerosos artículos suyos han sido publicados en revistas y periódicos de Latinoamérica y Estados Unidos, al igual que sus poemas y relatos.
} 
ni de una situación circunstancial, sino efecto de una búsqueda crítica de un "nuevo" lenguaje que da cuenta de una experiencia de vida anclada en un pasado y presente histórico individual (las propias vivencias recreadas del escritor) y colectivo (la mirada crítica de la sociedad colombiana en los últimos cuarenta años). Lenguaje que procede de su capacidad para transformar las formas literarias de sus antecesores inmediatos con los que rompe de manera evidente, pero que a su vez mantiene un diálogo permanente con dos vertientes literarias tradicionales latinoamericanas: el barroquismo de Lezama Lima, Cabrera Infante y Severo Sarduy; y la modernidad y experimentación de José Asunción Silva, Huidobro, Borges, Cortázar, Macedonio Fernández, Roa Bastos y García Márquez, entre otros. Es decir, aprovecha una tradición al incorporarse a ella y al mismo tiempo la altera buscando su propia propuesta.

Su obra se caracteriza formalmente por el rescate y revaluación de técnicas exploradas por algunos de los anteriores escritores citados: desaparición casi total de la anécdota, centramiento en la subjetividad, reflexión especular, escamoteo lingüístico, fragmentación narrativa, enumeraciones disparatadas, proliferación y superposición de imágenes, transtextualidad, choque y condensación de significantes, parodia, interacción de distintas texturas lingüísticas, prodigalidad y derroche verbal, subrogación de lo útil, del diálogo directo y natural por un lenguaje abigarrado, caótico, lúdico, carnavalesco. Su narrativa es ante todo un ejercicio de libertad formal donde se observa una tendencia a la movilidad, al descentramiento, a la desconstrucción, a la constitución de otra naturaleza distinta donde el supuesto absurdo y caos instauran un orden peculiar. Es "la apoteosis de artificio", de la ironía, de la irrisión de la naturaleza, de un proceso de enmascaramiento, de envolvimiento progresivo y de inmersión en el panteísmo (Sarduy 169), cuyos dioses se instauran en el orden de cada discurso y en particular, en cada uno de los tres libros de relatos: El demonio y su mano (1975, diez cuentos), La casa de los vespertilios (1982, nueve cuentos), La esquina del movimiento (1992, doce cuentos) y en su novela Un día entre las cruces (1993).

En sus relatos la realidad se bifurca en múltiples dimensiones, cada una de las cuales remite a otras más profundas. Lo que los personajes protagonistas de esas historias intuyen y perciben, son otros ojos ocultos muy en el fondo de sí que vigilan, auscultan, diseccionan y reflejan cada uno de sus actos como en un espejo; son ojos que atalayan como si fuera Otro en un juego de alteridades (en "Viejos circulantes", "La piel del diablo"). En un momento o situación cualquiera, personajes unos, actores otros, actantes los demás, comienzan a desempeñar y encarnar oficios singulares: cables que unen y liberan, animales que destajan y reconstituyen, escribidores que escrituran y borran, gigantes que arrasan, escaleras que suben y bajan, en fin, es el inicio al camino a otros mundos que conducen al encuentro con ese Otro, su otro, que, asimismo, lleva la huella - la del origen - y su propia piel (en "Piel de gallina", "Tahalí", "Cables"). Aquí y allá —en los sucesivos textos- los personajes parecieran despertar de sucesivos sueños que vienen de tiempo atrás porque la realidad les es ajena; ahora quieren vivenciarla, descubrir el ser carnal que hay detrás de ellos y el mundo que les pertenece; desean despertar para entrar en otro sueño cuya realidad se funda en un pasado de cotidiana existencia: calles, casas, puertas, ventanas, balcones, cuevas, abismos, esporas, puentes, ríos, nubes, hongos, demonios y vespertilios. Estas imágenes, como esquirlas, se incrustan por todos los resquicios del cuerpo y los dejan tatuados para siempre. En ese sueño de mañana hecho hoy se entrecruzan disímiles realidades que dejan el aliento 
en vilo, incierto el pensamiento y acezante la imaginación. Tales realidades llevan en sí el peso de la imaginación y de los sueños y son inasibles en la misma medida de su concreción; son olas de mares remotos que retornan porque llevan en sí algo de lo originario y también son remanentes de un pasado suspendido pero no claudicado. Obsedidos en esas búsquedas, los personajes de muchos de los relatos regresan lentamente de extraños estados para acercarse a una realidad que no podrán asir, para sumergirse de nuevo - -en su huida, locura o muerte- en otros sueños (en "Pedazos de la cola de un animal gris"; "Astros, lastres y lustros"; "Testis unus, testis"; "Neuronita").

En los relatos, al igual que en la poesía y en la novela, Romero aborda la creación literaria - sin importar el género, que queda abolido por su renovado experimentalismocomo un pretexto para el despliegue de lo imaginario, de lo lúdico, del juego verbal que hace ver lo virtual como real y viceversa (en "El etíope de cuatro ojos", en "La casa de los vespertilios" o en "Una mariposa en la escalera"). Como sostiene el protagonista del relato "Prolegómenos sobre el tema del viajero o método eficaz de extraer linfocitos":

Uno puede mirar en distintas direcciones sin darse cuenta de que quien lo interpela se encuentra a su espalda. Es el problema de las ubicaciones. Uno se entusiasma por el espacio absurdo existente entre la acción de un hombre y la del otro.

Lo imaginario en el escritor no deriva sólo del ejercicio in extenso con el lenguaje, del juego con las palabras, sino también de la realidad concreta del país de origen (Colombia, donde la realidad desborda cualquier acto de imaginación) y de otros de adopción (Venezuela, Grecia, Estados Unidos), de una infancia (en Cali) pródiga en motivos para la imaginación y la creación. El universo literario que exterioriza un estado de realidad bajo la mediación de una visión del mundo, autogenera otro universo -éste, discursivo- que penetra, fisura y pone al desnudo el primero: son las caras de una misma moneda que se juega al albur al no hallar respuesta que satisfaga. Lo que es y no es al mismo tiempo, entroniza una situación de incertidumbre que se vuelve ley (en "Entre música, sonrisa y gasolina"; "Visite el planetario municipal"); muestra la condición de un ser encerrado en un laberinto cuyos pasadizos multiplicados al infinito conducen al ineludible pasado - al de las memorias primeras - o a ninguna parte (en "Pedazos de la cola de un animal_gris", "Neuronita", "El monje del peaje"). En muchos de sus textos se observan ciertos estados de conciencia y de imaginación en los que la palabra pone a funcionar por acción o reacción infinidad de formas y sentidos. Ella es propiciadora y engendradora de nuevas realidades posibles e imposibles; se torna goce delirante del verbo (en "El demonio y su mano", "Los hongos se nos siguen adelantando").

El epígrafe de Barthes que inaugura el libro "La casa de los vespertilios", indica la naturaleza del trabajo creador de Romero: no es la persona del otro la que urge, es apenas un simple pretexto para quedarse fijado en el espacio multiforme y en las palabras; para rebujar ambos y descubrir en ellos un juego infinito de posibilidades. El espacio se torna urgencia, forma y sentido. Él es el constituyente primario y la realidad multiplicadora que determina el quehacer y el ser de los otros. En esa búsqueda del espacio se da la posibilidad de "una dialéctica del deseo, de una imprevisión del goce" verbal (Barthes 11). Pero es en este proceso de pérdidas y ganancias, de ausencias y presencias, de ser y parecer en el que 
el juego, verbalizado, es determinante. ¿No es acaso el lenguaje hecho literatura un juego y un sistema peculiar de posibilidades infinitas? En La casa de los vespertilios todo es posible: desde el espacio que se bifurca y patentiza en mil formas y rostros hasta el goce con las palabras y el juego de azar en busca de iluminaciones a preguntas por lo más originario del ser del escritor y creador, que coinciden con algunas de su ser colombiano.

En los relatos que oscilan entre lo real maravilloso y lo fantástico: "Versión completa y verídica de la historia de la cacería del Gigante por Croar, Croir, Crour"; "Piedra caída del cielo"; "Astrolabio, el sencillo" o en "Semana santa", tienen asiento los grandes mitos universales, especialmente los cosmogónicosy apocalípticos. Con fino humory parodiando muchos de aquellos mitos, Romero los recrea de manera peculiar y los desmitifica atribuyéndoles nuevos sentidos o interpretaciones; con ellos pretende instaurar otros estados de realidad con los que busca su permanencia. Al decaer o desaparecer un mito, otro $\mathrm{u}$ otros vienen en su reemplazo recreando los primeros o el primero, origen de todos.

Transgredir e iniciarse en espacios supuestamente vedados como el valle del Gigante, el planetario municipal, el monasterio de "El monje en el peaje", el umbral de "A puerta cerrada", la cómoda de espejos de "El sueño elíptico de Dabaibe", es poder acceder a estados donde operan otras nociones de tiempo y espacio; basta intentar abrir una puerta, muro, ventana, escalera, cenobio cerrado, para que los personajes experimenten una sensación de vértigo en su viaje real o imaginario; es un irse yendo más allá de esa frontera que alucina, que se transfigura en río, espora, puente, camino sin fin, casa en ruinas, silbidos de animal, mujer llena de nubes, árbol de oro, tahalí, esciápodo, mentícora, hipópodo, cinocéfala. Cruzar ese confín que es y no es a la vez puerta de acceso, lleva a los personajes a una pérdida de su condición real. Ellos se pierden tras lo siempre buscado, lo Otro, su Otro; realidad siempre inasible, dominio de la noche y el sueño. Es precisamente en el momento de atravesar el límite que lleva del más acá al más allá imaginario cuando se vive el vértigo del instante y de la transgresión, que es a la vez de afirmación. Espacio (umbral), tiempo (instante, pasado originario), búsqueda (campo de expectativas), se vuelven realidades ontológicas. En el momento mismo en que se cruza cualquier límite, se produce en los personajes un despojamiento de su realidad material para investirse con un ropaje fantasmático como el de los deseos o los sueños. La superación de lo espacio-temporal, los hace partícipes de nuevas realidades que se multiplican al unísono.

Personajes como los de "La casa de los vespertilios", "Una mariposa en la escalera", "La piel del diablo" e "Historias de dos en el cenobio", viven una relación de encuentros y desencuentros, de acercamientos y abandonos, de sentimientos diversos producto de estados de vigilia o sueño, de realidad o imaginación, de orden y desorden, de simetría y alteración. En esos lugares: casa, escalera, ojo ciclópeo que emerge del centro de la plaza, monasterio, no se sabe si el desorden que reina es efecto de un orden, de un previo desorden, de un orden de éste, o de la simultaneidad de éstos. Es imposible hacer uso cabal de los espacios por su irregularidad y movilidad esperpéntica: lo que se recibe expulsa, lo que succiona vomita, lo que entra sale, lo que baja sube y viceversa. Lo que se cree que es casa, escalera, plaza, cenobio, se torna agua, mariposa, ojo, aire. Todo se mueve de manera inexplicable, cambia de lugar, de naturaleza. Hasta lo que se refleja en los ojos de unos y otros se modifica sin que haya ninguna aparente mediación. Es la acucia del instante que de súbito hace instalarse en otra realidad como si se navegara por los senderos alucinados 
de los sueños o pendieran de un hilo fantasioso en donde todo es posible. Es esta una manera de señalar la inserción del relato en el código de lo fantástico que promueve un efecto de incertidumbre pragmático a partir de un acontecimiento de doble referencia: natural y sobrenatural (Chiampi 63).

¿Es acaso la casa, el castillo, la catedral, el monasterio representación de esa otra parte del ser, de lo invocado porque remite a un más acá en el tiempo y a un más allá inesperado, de lo siempre deseado de posesión y sometimiento, de lo que arroba por su misterio y brillo, en fin, de lo inasible? ¿Son acaso esos espacios obsesivos, por lo cotidianos y extraños, ventanas del alma, representaciones del lenguaje, espacios de la poesía que muchos creen poseer, pero muy pocos logran penetrar y conocer sus recónditos secretos? O acaso como dice el protagonista: "es posible que el lenguaje no sea yo, y se apaguen las palabras". En ese juego de alteridad, contradicción y paradoja, la palabra es la única y posible conjuradora de cualquier acto de realidad o imaginación, la que virtualiza todo y todo dimensiona para satisfacer a los ávidos lectores y su libertino imaginar.

Elmar como término, como lugar deseado, como espacio de disolución y substanciación, inaugura y concluye la novela Un día entre las cruces. Es un texto en forma de trípticoizquierda, derecha, centro- que se muerde la cola: de la infancia de Elipsio, marcada por la violencia partidista de los años cincuenta y sesenta, se pasa a las vivencias iniciales con los nadaístas y la visión de la anarquía e insolencia de ese movimiento, y, luego, a la extinción en vida del protagonista en la cárcel que refleja la presencia constante de la muerte, el cuestionamiento de la doble moral y la capacidad de olvido de una sociedad que deja una profunda e imperecedera huella en el alma de Elipsio, y por ende, en el narrador, demiurgo en ausencia y cuya presencia se siente. En la novela se observa el estado de disolución, de arrasamiento que acompaña el despertar adolescente de Elipsio bajo los efectos enervantes, equívocos del nadaísmo disoluto e irreverente. La experiencia del protagonista como joven editor de una revista nadaísta hace de él un eterno exiliado, un ser en busca de algo sustancial imposible de asir mientras no se desplomen los numerosos obstáculos (de los distintos aparatos ideológicos del Estado) que se interponen en un camino sembrado de cruces.

Más allá del cerro que bordea la ciudad, se halla el mar que tanto desea Elipsio. El tiene que librar una lucha sin pausa ni tregua, exponer al desnudo su propia piel para alcanzarcon ascesis por el despojamiento y escarnio que debe padecer - la fusión esperada con su origen primero y con el más inmediato, el mar cercano de Juanchaco y Ladrilleros que se vuelve, por su propia urgencia, en signo de vida. Hay que desmoronarlo todo, socavar las entrañas de la ciudad y las de las montañas que la cercan (la de las cruces) para hallar en su oscuridad fetal el camino de regreso a la unidad inicial, como el héroe épico que retorna luego de la aventura de mil batallas al haber logrado la unidad del hombre con el mundo, rota antes. En el camino del descenso (de la montaña de cruces institucionales) al infierno (de la ciudad) Elipsio deja pedazos de sí por doquier para reintentar el ascenso con su fardo en busca del añorado mar (más allá de las montañas de las cruces) y el paraíso para siempre perdido (el de la primera infancia).

La imagen final del primer capítulo se reitera, de manera peculiar, en el segundo y tercero. En el primero, cuando una marabunta en carnaval de millones de hormigas comienzan, en el patio de los juegos infantiles de Elipsio y de su hermano Francisco, a arrasarlo todo en su viaje disolutivo hacia el mar, el toque de queda resuena por todas partes 
convirtiendo el día en noche, el fin en principio de un funesto amanecer, el caos en nuevo orden, lo sólido en proceso de desmoronamiento. Es el viraje hacia la "Izquierda" que rompe, que fisura todo orden, que genera la incertidumbre y con ello la posibilidad de cambio. En el segundo capítulo, en medio de la noche en un apartamento de una ciudad cerrada por los fragores de una guerra civil no declarada contra los que pretendan subvertirla, Elipsio vive tiempos de prisa y de escondites, de palabras clandestinas en sus poemas y en la revista Ovulo y esperma. El es la expresión de orfandad de un grupo contestatario a las normas e instituciones en una sociedad estatizada en el pensamiento y la moral, normas fijadas para siempre como en moldes de piedra (las estatuas de parque que sólo rememoran el pasado atávico). Elipsio, Lamia y unos cuantos como ellos representan, para "las fuerzas vivas" de la sociedad colombiana, un atentado, una provocación inmoral, el ejercicio de un discurso, el propio, contra el discurso institucional que pretenden desenmascarar.

Desde su laberinto —en la tercera parte-Elipsio alcanza a deslizarse, huyendo de los represores del Estado, hacia el vacío de oscuras sombras que le llevará a una muerte en vida; es el viaje de vértigo, de náusea que le provoca la jaula de hierro donde es recluido; desde allí comienza el descenso sin límite hacia su disolución moral; es el viaje al abismo baudelairiano. La cárcel oscura hace de él un ser sin identidad, porque previamente su nombre ha sido borrado de cualquier lista. En ese viaje al infierno, la "Derecha" es la que determina el pensamiento, la moral y las costumbres, es el status quo mental que con su lastre del pasado fija todo para siempre; se niega el cambio y a quienes pretenden generarlo se los somete al escarnio o al olvido absoluto.

Al final de la novela se muestra a Elipsio sentado en un vagón de tren a la espera de una partida hacia tan anhelado mar; repasa como en una película su estadía en el infierno de la prisión, la huida por un túnel que lo vuelve a la vida, la que había perdido al haber sido eliminada su identidad y cualquier asidero con la realidad. Se pone de presente la vivencia de una existencia, que al ingresar a la cárcel, pierde fundamento para el mundo porque una decisión del sistema represivo del país hace desaparecer todo vestigio de él; se le otorga una nueva carta de identidad, no existir. Desde ese lugar del infierno, Elipsio ve a la sociedad en camino vertiginoso hacia el vacío por el estado de descomposición interna, por aferrarse a un pasado lastrado de falsa moral y de desconfianza al mundo exterior; es el derrumbe total de las instituciones y del Estado (Oquist 227-71). Los últimos goznes y resortes de una moral esclerosada ceden a la avalancha de la turbamulta de niños-fieras que, enfurecidos, avanzan con pasos de cataclismo hacia el "Centro", engullendo, destrozándolo todo, hasta no dejar rastro alguno: es el "orden de un gran desorden" y el tiempo de apocalipsis que no dará ocasión a una segunda oportunidad. Elipsio, como un fantasma en medio de aquel festín del caos, de aquel vórtice que deglute los últimos vestigios de una sociedad enajenada por su odio atávico, por su encerramiento de siglos, ríe, al liberarse de ese pasado que le ha atado la rueda al cuello hasta el final de sus días. Ahora ya es otro que vivirá en otros seres más allá del tiempo y el espacio y terminará en el mar, diluido, transustanciado.

Es el anuncio definitivo del ocaso, del fin de una historia que pretende ser el comienzo de otra, aunque no se vislumbra cuál podría ser. A la izquierda de la casa está el mar a donde se dirige y viene cada semana Argemiro con su valioso cargamento que comunica a los hombres. A la izquierda está el barrio obrero donde casi todos eran liberales. De la izquierda 
proviene el libre pensamiento, el laicismo de vida, la fe en la razón y el ejercicio de la imaginación. Es ese espíritu que el joven Elipsio antepone en su manera de ser y de pensar. De su espíritu de izquierda y de su anarquismo utópico nace el riesgo y la osadía, pero también el sentimiento de fracaso ante un discurrir histórico sembrado de cruces desde el fondo, el subfondo y la superficie.

Así sea de modo provisional, vale la pena apreciar el ars combinatoria, los apoyos procedimentales en torno a los cuales se supone gira toda la narrativa de Romero y a los que permanentemente apela para darle salida a sus fantasmas de creación: un yo que se desdobla en otro, acciones que siempre plantean su regresión, finales que decepcionan la expectativa del lector, descentramiento continuo, desconstrucción discursiva, historias en espiral, de suerte que los relatos se mueven en una especie de vaivén paradójico. En efecto, en el escritor opera un procedimiento cognitivo de creación que es precisamente la paradoja, paradoja narrativa y no retórica porque sus relatos se mueven a fuerza de parecer contradecirse, así obtienen su fuerza de movimiento, a fuerza de ir y volver como en zigzag. Son una especie de construcción en telaraña, "hifológica" la llama Barthes: "el texto se hace, se trabaja a través de un entrelazado perpetuo; perdido en ese tejido - esa texturael sujeto se deshace en él como un araña que se disuelve en las segregaciones constructivas de su tela ... Es un velo detrás del cual se encuentra más o menos oculto el sentido (la verdad)" (Barthes 81). Romero trabaja así, en forma de costura en telaraña. En medio del experimentalismo, es una construcción inteligente que viola el contrato mimético porque está permanentemente invitando al lector a tejer y destejer, de modo que el lenguaje, al tiempo que muestra visos referenciales, postula a la vez formas autoreferenciales, con lo cual se pone a tono con el gran movimiento de la época que insiste en recuperar metalingüísticamente todas las instituciones propias de lo literario.

En la proliferación, interacción, yuxtaposición, disloque de espacios, los personajes y/ o narradores de los treintaiún relatos y una novela de Romero experimentan un peculiar goce que hacen de ellos objeto de divertimento, irrisión y juego. El espacio cumple una múltiple función: por él se va, se viene, se desliza o se fuga; es el juego de la rayuela que en cualquier instante, aun en el menos pensado, se puede quedar atrapado inmediatamente o para siempre en uno de los umbrales que separan esos dos espacios cuyas fronteras, cielo e infierno, apenas si se reconocen. En "La casa de los vespertilios", en "La puerta cerrada", en "Neuronita" y otros tantos relatos, no se sabe si cuando se entra se sale, si al entechar se desenteja, si acostarse implica despertar, si ausentarse es hacerse presente, pues más allá y al instante de cualquier acto pareciera realizarse el contrario; nuevas realidades sorprenden al lector. Es el juego con "los magos de los espejos que se divierten con las formas para resolverlas en una fantasmagoría en la cual el sujeto pierde el hilo que lo mantiene unido al mundo" (Dubois 35).

Lo que en opinión de Calzadilla da unidad al texto de Romero es el doble carácter metafórico del lenguaje "en tanto que figuración de una realidad abstracta que se inventa aquí como un mundo macroscópicamente larvario; y en tanto que proceso que pone al descubierto los mecanismos de la invención anecdótica" (Calzadilla 641). Uno de esos mecanismos efectivos es el de funcionar mediante imágenes obsesivas e ideas fijas que circulan casi naturalmente por toda su obra, imágenes e ideas que remiten necesariamente a la búsqueda y encuentro con el lenguaje, de ahí la razón de García Maffla cuando sostiene 
que "La casa de los vespertilios" [igual se diría de la mayoría de sus relatos] "es la casa del lenguaje ... En estos relatos, lo propuesto es el acto de escribir, de relatar que es como ir edificando, con la misma dimensión e intención que los insectos: ya no es el lector quien recibe el lenguaje sino el lenguaje quien acepta al lector" (García 48).

El ánimo del lector está siempre al asalto por los estados de imaginación cambiante que se observa en la singular escritura de Romero, la que no deja un solo momento para el acomodamiento por su condición lúdica y por la naturaleza de su entramado. Cuando se cree que se ha aprehendido una imagen, una forma de realidad, un sentido, inmediatamente aparecen otros nuevos o sus contrarios; lo que parece ser, a la vez es y no es; hay siempre un nuevo orden o su desorden; es la afirmación de la equivocidad, de la ambivalencia, del ser y el parecer (en "Viejos circulantes", "Prolegómenos sobre el tema del viajero o método eficaz de extraer linfocitos", "El monje del peaje"). Nada es definitivo, asible, absoluto: todo interactúa y multisignifica según el objeto de percepción y recepción de narradores y narratarios. Toda su obra pareciera un esguince de la realidad histórica a través de los artificios del lenguaje que tan bien maneja, un "escamoteo de una esencialidad cuya ausencia deja al hombre desamparado y sumido en la angustia del sin sentido" (Bustillo 122) (en "Entre música, sonrisa y gasolina", "El demonio y su mano", "La esquina del movimiento"). La mayoría de sus relatos se caracterizan por su permanente descentración a la manera derridiana (Derrida b, 269-271). Si bien todo texto presupone una sintagmática y una paradigmática, al mismo tiempo implica un centro imaginario que es completamente descentrado en cada una de las unidades, nunca se llega a centro alguno por su movilidad permanente (en "El sueño elíptico de Dabaibe", "Una mariposa en la escalera", "El etíope de cuatro ojos"). Como la descentración, el principio de reversibilidad es otro recurso utilizado en su narrativa al anticipar el efecto cuando se debe enunciar la causa y se pospone la causa cuando se menciona el efecto (Vélez 27-28) (en "La casa de los vespertilios", "El sueño elíptico de Dabaibe").

Relatos como "Tahali", "La esquina del movimiento", "El monje del peaje", "Historia de dos en el cenobio" o "El etíope de cuatro ojos" entre otros, por su temática y tratamiento, se inscriben en la literatura fantástica al privilegiar un narrador predominantemente homodiegético, porque, como lo señalara Todorov, de todos los pronombres en español el yo es el que pertenece a todos y como quiera que el yo es aquel que por primera vez siente la indeterminación, la incertidumbre en ese yo representado se traslada con un efecto pragmático discursivo al lector, de suerte que se hace simbiosis entre el personaje que dice yo dudo y el lector que también duda (Todorov 122-24). Funciona aquí el principio de alteridad que, en la opinión de Bakhtin, es el que permite que el yo complete el imaginario que él tiene de su propia identidad; es sólo por lo que el otro le dice que el yo puede ir completando su propia identidad escindida (Bakhtin 157-172). Ónticamente venimos al mundo separados y vamos tras la búsqueda de algo que de alguna manera restituya aquella antigua unidad perdida - la nostalgia del paraíso perdido (D’Ors 31). La única opción es el lenguaje que Uno da al Otro, porque en ese lenguaje se compromete parte de la imagen que el Uno tiene del Otro y que no alcanza a tener de sí mismo; es por eso que el primero dice de su alter ego lo que lentamente va constituyendo el restablecimiento de la unidad. Al respecto es bien comprensible la idea de Brodsky de que nunca el espejo nos devuelve la identidad, sino la anonimidad (Brodsky 24). Quien puede restituir la identidad es el otro con su lenguaje. 
En la interacción y orquestación, a manera de juego, de tantos componentes formales y temáticos en la escritura de Romero, una imagen hace presencia: la de una realidad barroca que en su egregia posición - siguiendo sus mismas palabras- "espejea todos los cambios en su constante movimiento, permite hacer cuerpo su visión del mundo americano, juega todas las combinaciones de lo real a fin de corporizar la imagen que se multiplica de acuerdo a las necesidades y urgencias de nuestra imaginación" (Romero 1989, 12). Sus relatos y novela son, siguiendo a Derrida, un intercambio de presencias y ausencias, de azar y de riesgo absoluto (Derrida a 386); de convergencias y divergencias, de goce y provocación; son, como señalara Barthes hablando de "Cobra" de Severo Sarduy, una "fiesta", en la medida en que "la lengua se reconstruye en 'otra parte' por el flujo apresurado de todos los placeres del lenguaje. ¿En qué otra parte? En el paraíso de las palabras. Es verdaderamente un texto paradisíaco, utópico(sin lugar), una heterología por plenitud: todos los significantes están allí pero ninguno alcanza su finalidad; el autor (el lector) parece decirles: 'os amo a todos' (palabras, giros, frases, adjetivos, rupturas, todos mezclados: los signos y los espejismos de los objetos que ellos representan); una especie de franciscanismo convoca a todas las palabras a hacerse presentes, darse prisa y volver a irse inmediatamente: texto jaspeado, coloreado; estamos colmados por el lenguaje como niños a quienes nada sería negado, reprochado, o peor todavía, 'permitido'. Es la apuesta de un júbilo continuo, el momento en que por su exceso el placer verbal sofoca y balancea en el goce" (Barthes 1516).

Bibliografía

Bakhtine, M. Esthétique et Théorie du roman. París: Gallimard, 1978.

Barthes, R. El placer del texto. México: Siglo XXI, 1974.

Brodsky, J. Marca de agua. Santafé de Bogotá: Norma, 1993.

Bustillo, C. Barroco y América Latina. Un itinerario inconcluso. Caracas: Monte Ávila, 1988.

Derrida, J. De la gramatología. Buenos Aires: Siglo XXI, 1971.

"Estructura, signo y juego en el discurso de las ciencias humanas". Los lenguajes críticos y las ciencias del hombre. R. Macksen y E. Donato. Barcelona: Barral, 1972. 269-287.

Calzadilla, J. “La casa de los vespertilios”(reseña), Revista Iberoamericana 123-124 (abrilsetiembre 1983): 641.

Chiampi, I. El realismo maravilloso. Caracas: Monte Ávila, 1983.

D’Ors, E. Lo barroco. Madrid: Aguilar, 1964.

Dubois, J. El manierismo. Barcelona: Península, 1980.

García Maffla, J. "La voz profunda del misterio". Cromos 3495, 48. Bogotá, 8 abril 1985.

Oquist, Paul. Violencia, conflicto y política en Colombia. Bogotá: IEC-Banco Popular, 1978.

Rama, A. "Diez problemas para el novelista latinoamericano". La novela hispanoamericana. J. Loveluck (comp.). Santiago: Universitaria, 1969. 277-336.

Romero, A. El demonio y su mano. Caracas: Monte Ávila, 1975. La casa de los vespertilios. Caracas: Monte Ávila, 1982. 
La esquina del movimiento. Caracas: Alfadil, 1992.

Un dia entre las cruces. Santafé de Bogotá: Tercer Mundo, 1993.

Gente de pluma. Madrid: Orígenes, 1989.

Sarduy, S. "El barroco y el neobarroco". América Latina en su literatura. César Fernández Moreno (comp.). México: Siglo XXI, 1972. 167-84.

Todorov, T. Introduction a la littérature fantastique. Paris: Seuil, 1970.

Vélez, M. "Disposición de la alternancia en el relato literario". Contex-tos. Revista de semiótica literaria 8. Medellín, 1991. 27-28. 